\title{
CONTROLE DE VARIÁVEIS NUM GRUPO DE ATENDENTES EM TREINAMENTO
}

\author{
Maria Cecilia Manzolli * \\ Maria Aparecida Minzoni **
}

O treinamento de pessoal de enfermagem para psiquiatria é um assunto que tem sido motivo de preocupação há longo tempo. Toda atividade nesse sentido tem se constituido em valiosa experiência, desde que se passa a analisar os erros e os acertos e a procurar controlar certas variáveis que provavelmente influem nesse processo.

Assim, quando se planeja uma experiência de treinamento para atendentes psiquiátricos procura-se controlar, em um grupo experimental, algumas variáveis relacionadasi às condições individuais de cada participante. Estas condições se referem, entre outras, à idade, escolaridade, sexo, inteligência, motivação e personalidede.

Nesse planejamento partiu-se da idéia de que existem, interferindo no treinamento, fatores ambientais como a organização social da instituição, o tipo de chefe e fatores relacionados a variáveis inerentes ao próprio indivíduo. Desse modo, o processo de ensino rão depende apenas das habilidades do "agente" (treinador) mas, também das condições do "aprendiz" (treinado).

Ainda deve-se lembrar que podem estar, presentes durante a fase de treinamento, outras variáveis como as características próprias do instrutor, os reforços empregados, as instruções e as avaliações utilizadas.

No presente estudo procurou-se analisar os resultados de alguns testes utilizados para controlar as condições inerentes aos participantes do treinamento. As variáveis estudadas foram as seguintes:

* Psicóloga do Departamento de Enfermagem Psiquiátrica e Ciências Humanas da EERP-USP.

** Enfermeira psiquiátrica do Departamento de Enfermagem Psiquiátrica e Ciências Humanas da EERP-USP. 
sexo, idade, estado civil, escolaridade, inteligência, personalidade e opinião dos atendentes sobre seu chefe.

E importante salientar que tanto os professores quanto os atendentes não tiveram acesso aos dados nos testes de personalidade $\mathrm{e}$ de inteligência.

\section{POPULAÇÃO}

Trabalhou-se inicialmente com um grupo de 20 atendentes de um hospital psiquiátrico, escolhidas aleatoriamente. Entretanto, este grupo passou a constar de 17 elementos, pois dois alunos entraram em férias e um abandonou o curso.

O treinamento teve a duração de três meses com duas aulas de duas horas e um grupo de discussão, por semana.

\section{MATERIAL}

Foram utilizados os seguintes instrumentos para obtenção dos dados: questionários e testes.

Os questionários eram dois. Um para coleta de dados relativos à identificação do indivíduo e outro para obter dados sobre a opinião do atendente em relação ao seu chefe. Foi usado para este último o questionário "Como Chefiar",(1) porém com objetivos diversos do original, pois este questionário permite "considerar a posição do examinando em relação ao grupo, isto é, entre os melhores ou os piores "chefes".

Os testes foram dois: Teste coletivo de inteligência para adultos, CIA(4) e Inventário de Personalidade de Bernreuter(3).

Convém salientar que os dados obtidos constituem apenas pontos iniciais para atingir os objetivos propostos, pois há necessidade de uma bateria de testes mais ampla para se fazer um estudo mais completo.

\section{RESULTADOS}

A população que concluiu os testes e o curso era constituida por 17 sujeitos sendo 9 do sexo masculino e 8 do sexo feminino; 11 solteiros, 5 casados e 1 viúvo; a idade variava de 20 anos e 1 mês a 41 anos e 6 meses; e a escolaridade compreendia desde a $6 .^{a}$ série até $2 .^{\circ}$ colegial.

$\mathrm{Na}$ aplicação do questionário "Como Chefiar" pediu-se aos examinandos, que respondesse como "viam" seu chefe e as ações do mesmo. Dos 17 sujeitos do grupo, apenas 15 responderam a este questionário. Esses dados encontram-se na tabela número 1. 
TABELA 1 - Como os atendentes "veem" seu chefe (em percentil)

\begin{tabular}{c|cc}
\hline & \multicolumn{2}{|c}{ População } \\
\cline { 2 - 3 } Percentil & Freqüência & Percentagem \\
\hline 1 & 1 & 52 \\
5 & 5 & 6 \\
10 & 1 & 33 \\
30 & & 6 \\
\hline TOTAL & 15 & 97 \\
\hline
\end{tabular}

Observações: a coluna de percentil indica "qual a porcentagem de um grupo representativo de chefes que poderia obter resultados inferiores a essa nota".(1)

Observa-se pela tabela que os chefes foram colocados pelos atendentes nos percentis baixos, pois quase a totalidade da população ( $91 \%)$ não lhes conferiu percentil superior a 10 , e o máximo atingido foi 30, quando na escala pode-se chegar até 100 .

$O$ teste usado para inteligência - CIA - fornece dados relativos ao conjunto total e também específica a inteligência verbal e não verbal. Esses três dados serão apresentados nas tabelas número 2 e 3 respectivamente.

TABELA 2 - Resposta ao conjunto total, avaliado pelo CIA.

\begin{tabular}{l|cc}
\hline \multirow{2}{*}{ Classificação } & \multicolumn{2}{c}{ População } \\
\cline { 2 - 3 } Inferiores & Freqüência & Percentagem \\
Normal inferior & 1 & 6 \\
Normal superior & 8 & 28 \\
Superior & 1 & 56 \\
& & 6 \\
\multicolumn{1}{c}{ TOTAL } & 14 & 94 \\
\hline
\end{tabular}


TABELA 3 - Resposta ao conjunto verbal e não verbal, avaliado pelo CIA.

\begin{tabular}{r|rrrr}
\hline & \multicolumn{2}{c}{ Verbal } & \multicolumn{2}{c}{ Não Verbal } \\
\cline { 2 - 6 } Classificação & $\mathbf{N} .^{0}$ & $\%$ & $\mathbf{N . 0}$ & $\%$ \\
\hline $70-89$ & 1 & 6 & 3 & 21 \\
$90-99$ & 6 & 42 & 6 & 42 \\
$100-109$ & 7 & 50 & 4 & 22 \\
$110-119$ & - & - & 1 & 6 \\
\hline TOTAL & 14 & 98 & 14 & 91 \\
\hline
\end{tabular}

Legenda: N. $^{\circ}=$ freqüência de sujeitos

$\%=$ percentagem

Observa-se por estas tabelas, primeiramente, que pouco mais da metade $(56 \%)$ apresenta inteligência normal superior. Por outro lado, $34 \%$ está colocado em níveis inferiores de inteligência. Quanto a inteligência verbal metade $(50 \%)$ obteve elevado número de pontos, o que não ocorre com a inteligência não verbal cuja maior freqüência de sujeitos $(42 \%)$ está no intervalo $90-99$.

A avaliação das características de personalidade foi feita utilizando-se o inventário de Bernreuter que fornece dados indicando os seguintes traços: tendência neurótica, auto suficiência, introversãoextroversão, dominância-submissão, confiança em si mesmo e sociabilidade.(5)

Após a avaliação dos dados considerou-se a freqüência dos sujeitos nos percentis dos seis traços. Essa freqüência é a apresentada na tabela 4. 


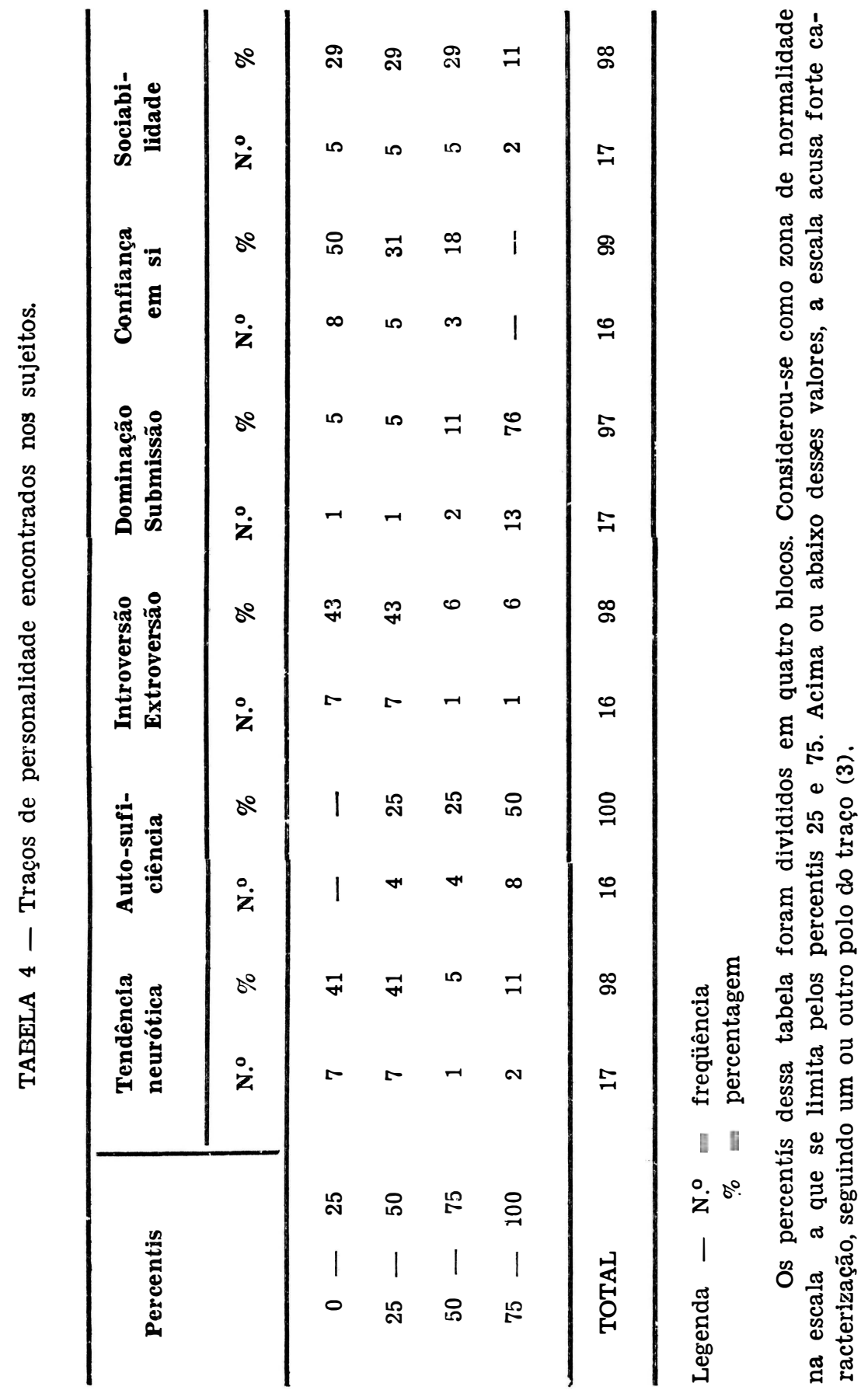




\section{DISCUSSÃO}

Observando-se o grupo de atendentes selecionados para esse estuơo verifica-se que são heterogêneos em relação à idade e à escolaridade. Essa é uma situação que pode interferir no treinamento, mas ao mesmo tempo é uma amostra do que se encontra nos hospitais psiquiátricos, de modo geral.

Verificou-se, também, pelos dados apresentados na tabela 1 que todo grupo considerou seus chefes num percentil baixo (máximo 30 ). Isto pode indicar que os atendentes podem estar insatisfeitos com seus chefes e é possível que essa insatisfação se constitua numa barreira para que reformulem seu comportamento na prática profisisonal, segundo o treinamento recebido. i possível, também, que adquirindo maiores e melhores conhecimentos sobre o desempenho de suas atividades e não tendo o apoio dos chefes possam regredir além do que eram antes do treinamento, chegando a agravar o relacionamento entre si, com o chefe e com os pacientes.

Também, quanto à inteligência encontrou-se uma variabilidade desde niveis inferiores até superiores. Este aspecto dificulta o treinamento e provavelmente exige o uso de técnicas didáticas diferentes, de acordo com os indivíduos. Por outro lado, lembra a não existência de uma seleção mais acurada para se admitir um funcionário.

Um dado importante, sob esse aspecto, é a maior facilidade demonstrada pelo grupo em utilizar a inteligência verbal. Isto é positivo quando se pensa que técnicas onde predominam o comportamento verbal como entrevista, atividades para socialização, muito importante em enfermagem psiquiátrica. Este ponto pode ser realçado no treinamento, com uso de técnicas de aprendizagem adequadas.

Com relação à inteligência não verbal surge uma questão que poderias ser objeto de investigações futuras: “será que sujeitos, cujos resultados no CIA apresentaram mais alta freqüência na parte não verbal, poderiam ser treinados para a execução de atividades predominante manuais? Se a resposta fôr afirmativa, os que apresentam resultados elevados em inteligência verbal, permaneceriam mais próximos dos pacientes?"

Quanto aos traços de personalidade observou-se, de acordo com os dados obtidos que a maioria da população (46\%) se apresentou com traços emotivos normais, $41 \%$ com alta moderação emotiva e $11 \%$ com elevada tendência no traço denominado tendência neurótica. Em relação a auto-suficiência eles se apresentaram moderados ou altamente auto-suficientes (50\% de cada lado). O grupo tende a ser. mais exitrovertido do que introvertido (apenas 6\%). 
Com relação aos traços' dominância-submissão os resultados indicam que os sujeitos demonstram ser mais dominantes do que submissos (76\% alta e $16 \%$ medianamente). Encontrou-se, também, a totalidade dos sujeitos confiantes em si, em maior ou menor escala ( $50 \%$ no valor alto e $49 \%$ no valor médio). A maioria (58\%) é sociável, embora observe-se a existência de sujeitos que atingem os limites extremos, para cima e para baixo, de sociabilidade (29\% alta e $11 \%$ baixa).

Uma avaliação conjunta desses traços indica que a grande maioria desse grupo pode ser colocada na zona aceita como adequada. Nó entanto, não se deve esquecer aqueles que fogem a essa classificação. E mais uma vez se levanta o problema de uma seleção mais cuidadosa do pessoal a ser admitido para trabalhar com doentes mentais, se fôr considerado importante a personalidade do sujeito. Quanto a isso, atualmente, tem-se reconhecido que são tão importantes as características de perșonalidade quanto a aptidão do indivíduo para c trabalho. Se há uma inadequação em qualquer dessas áreas, provavelmente, haverá fracasso,

Não se preocupou aqui, com uma análise de cada traço e sua importância no desempenho de tarefas específicas, nem se fez, como se disse anteriormente um estudo exaustivo da população focalizada.

Conquanto não se dispusesse de antecedente e tão pouco de tempo para colocar-se aqui a pergunta: até que ponto é válido o atendente de enfermagem de hospital psiquiátrico apresentar traços de personalidade que se assemelham aos dos próprios pacintes mentais?

\section{CONCLUSÕES}

De modo geral, verifica-se que essa população apresentava grandes diferenças quanto às variáveis idade, escolaridade e inteligência, por variarem em escalas amplas de um mínimo ao máximo.

Observou-se ainda sua insatisfação com os chefes e suas possibilidades de adaptação ao serviço quanto aos traços de personalidade apresentados.

Apesar de este grupo ter sido estudado sem a pretenção de se fazer generalização, ele indica alguns pontos que devem ser foco de atenção quando se pretende planejar o treinamento de pessoal e, no caso, de pessoal de enfermagem em serviço num hospital:

- em vista do exposto percebe-se: a necessidade de um melhor sistema de seleção para admissão do pessoal de enfermagem que trabalhará junto com os doentes; a necessidade de uma revaliação do pessoal já em serviço com um possivel remanejamento; a necessi- 
dade de treinamento do pessoal de acordo com as características individuais, tanto quanto devem ser levados em consideração as condições do ambiente; a necessidade do treinador estar preparado em técnicas de aprendizagem, bem como em relação ao processo de mudança.

\section{R.EFERENCIAS BIBLIOGRAFICAS}

1 - FILE, Quentin W. e REMMERS, H.H. - Como Chefiar. Traduçắ e adaptação de Eva Nick. Rio de Janeiro: Edições Cepa. p. 12-13.

2 - MORAES, Raul de; ANDRADE, Eugenia M. de; e ALVES, Dulce de G. Padronização de um teste coletivo de inteligência para adultos. Revista de Administração, 1962, 29.

3 - MORAES, Raul de e ANDRADE, Eugenia M. de - Manual para uso do Inventário de Personalidade de R.G. Bernreuter. São Paulo, U.S.P. - Instituto de Administração, 1952.

4 - MORAES, Raul de; ANDRADE, Eugenia M. de e ALVES, Dulce G. Teste coletivo de Inteligência para adultos, Teste CIA, Forma I, Manual Rio de Janeiro: Edições Cepa.

5 - SCHAEFFER, Ruth - Introdução aos testes psicológicos, Rio de Janeiro: Fundação Getúlio Vargas, serviço de publicações, 1962. 